\title{
Urban Agriculture: Fostering the Urban-Rural Continuum
}

\author{
François Mancebo ${ }^{1, *}$ and Sylvie Salles ${ }^{2}$ \\ ${ }^{1}$ International Research Center on Sustainability, Rheims University, Rheims, France \\ ${ }^{2}$ Ecole d'Architecture Paris Val de Seine, Paris, France \\ *Corresponding author: E-Mail: francois.mancebo@univ-reims.fr; Tel.: +33 612537446
}

Published: 20 April 2016

Urban agricultural projects have been mushrooming since the end of the twentieth century, reshaping urban landscapes and even the whole urban fabric, experimenting with alternatives to the traditional urban life, sometimes creating new commons, and bringing people together. Within a city, farmers, gardeners, and their neighbors share more than just fence lines. Cities already have a huge potential for farming. Three examples can be observed in very different cities around the World: Singapore, is fully selfreliant in meat, Bamako is self-sufficient in vegetables, and in Berlin there are 80,000 community gardens on communal land and 16,000 more people are on a waiting-list [1]. And this is just the beginning; in many cities new unbuilt areas emerge in the wake of deindustrialization (derelict lands, wastelands, brownfields, etc.), or as a consequence of urban shrinking due to aging populations (as in Japan or Germany), or of emigration (as in some African mid-sized cities). These new areas are a wonderful opportunity for urban agriculture. In Detroit, thousands hectares of urban land have been given over to unemployed workers for food growing. In Britain, urban agriculture has been promoted on wastelands of 20 cities by their various councils [2]. Urban agriculture is gradually becoming a planning policy option. In Delft, the planners of the city already combine urban agriculture with several other land uses in their planning documents; in Paris, an inclusive local land development plan protects agricultural landscapes [3,4]. Urban agriculture is neither-or no more-the short-lived remnant of a rural culture nor the hipsters' latest futile craze.

Yet, on the face of it, tying together these two wordsurban and agriculture - is not self-evident, even if city and agriculture have gone hand in hand for a long time: in fact, since Neolithic times and the first human settlements, as pointed by Paul Bairoch [5]. Jane Jacobs even promotes the idea that agriculture is of urban origin, and it was only later that agriculture migrates to the countryside - this was a very slow process [6]. It was only in the middle of the Twentieth Century, in the aftermath of the WW2, that cities and agriculture - which had always been inseparable-divorced. Increased mobility and progressive globalization made apparently pointless proximity between farmers and urban consumers. Farming was banned from the city by planning regulation. Urban agriculture suffered then from many political restraints: restrictive urban policy, laws giving an illegal status to urban agriculture, lack of supportive services, etc. Hopefully things are changing, and urban agriculture is being welcomed again in the city after an unfortunate interlude of some fifty years. Still in the Ninetieth Century the close interaction between city and farming could be read in the landscape and in the planning instruments and procedures. In 1826, Von Thunen's theory explained agricultural patterns near urban areas-in the form of concentric circles, with crop type being determined by transport cost-distance modeling. It was maybe a rough and restrictive draft of what we coin today as the importance of addressing the rural-urban continuum to deal with urban sustainability. Indeed, talking about urban sustainability is meaningless if we stop at the city limits. Everyone agrees today to consider that sustainable urban policies should take into account an urban-rural continuum that goes far beyond the dense mineral town within its administrative limits.

Urban agriculture may help designing truly sustainable policies for such complex settings. We need to question and discuss ways to include, in a perennial manner, agri- 
culture in urban policies. Urban agriculture can be seen as a process of hybridization between city and agriculture, which offers many advantages over other expressions of nature in the city. In addition to allowing the development of agricultural production, being consistent with the aspirations of urban populations wishing to reconnect with nature, and providing many ecosystem services, urban agriculture also provides new opportunities for developers to rethink the organization of the urban fabric. To facilitate this, there is a need for knowledge building (sharing examples, procedures, comparing different places), which should take the form of a co-production of knowledge by all the actors involved in urban agriculture actions through the world. Confronting and integrating values and knowledge from different stakeholders is crucial to help decision-making. This task was initiated by the international conference 5èmes Rencontres

\section{References and Notes}

[1] Smit J, Nasr J, Ratta A. Urban Agriculture: Food, Jobs and Sustainable cities. Series for Habitat II. New York, NY, USA: United Nations Development Programme; 1996.

[2] Deelstra T, Girardet H, et al. Urban agriculture and sustainable cities. In: Bakker N, Dubbeling M, Gündel S, Sabel-Koshella U, de Zeeuw H Growing cities, growing food Urban agriculture on the policy agenda Feldafing, Germany: Zentralstelle für Ernährung und Landwirtschaft (ZEL); 2000. pp. 43-66.

[3] Mougeot LJA. Growing better cities: Urban agriculture
Internationales de Reims on Sustainability Science whose theme was precisely "Urban Agriculture: Fostering The Urban-Rural Continuum". Most of the articles in this special issue of Challenges in Sustainability were presented on the occasion of this conference.

To capsulize into a few words what was the guiding thread throughout the conference, and therefore the unifying idea of this special issue beyond the diversity of the papers, the following can be said: When trying to determine if urban agriculture may contribute to a sustainable future, the primary question to ask is: Will this agriculture be at the service of the inhabitants? Its success depends on its objectives, its form, and its local ownership by the people concerned. It has a lot to do with building resilient communities. By doing so, urban agriculture can be the cornerstone that helps reconfigure more sustainable cities.

for sustainable development. International Development Research Centre; 2006.

[4] Mancebo F. Combining Sustainability and Social Justice in the Paris Metropolitan Region. In: Isenhour C, McDonough G, Checker M, editors. Sustainability in the Global City: Myth and Practice. Series New Directions in Sustainability. Cambridge, UK: Cambridge University Press; 2015. pp. 263-283.

[5] Paul B. De Jericho à Mexico, villes et économie dans l'histoire. Paris, France: Gallimard; 1985.

[6] Jacobs J. The Economy of the City. New York, NY, USA: Random House; 1969. 